\title{
SOSIALISASI DAN PEMERIKSAAN KARIES GIGI PADA SISWA DI SD NEGERI 5 WAAI KECAMATAN SALAHUTU KABUPATEN MALUKU TENGAH
}

\author{
Zasendy Rehena $^{1 *}$, Andriana R. Nendissa ${ }^{1}$, Dene F. Sumah ${ }^{1}$ \\ ${ }^{1}$ Fakultas Kesehatan, Universitas Kristen Indonesia Maluku, Ambon, Indonesia \\ *Penulis Korespendensi: rehenasasendi@gmail.com
}

\begin{abstract}
Abstrak
Program Kemitraan Masyarakat bagi siswa SD Negeri 5 Waai, dilakukan berdasarkan permasalahan yaitu masih rendahnya pengetahuan siswa tentang karies gigidan Usaha Kesehatan Sekolah (UKS) juga tidak dijalankan sehingga program Usaha Kesehatan Gigi Sekolah (UKGS) yang merupakan bagian integral dari UKS tidak dapat dilaksanakan.Tujuan kegiatan ini adalah meningkatkan pengetahuan dan kebiasaan menggosok gigi, pendampingan bagi guru untuk membuat buku panduan UKS, pemeriksaan gigi untuk mengetahui tingkat keparahan karies gigi pada siswa.. Metode yang digunakan yaitu pendampingan dengan metode FGD, penyuluhan, praktekmasal menggosok gigi, dan pemeriksaan gigi. Kegiatan ini dilakukan pada bulan Agustus 2019. Hasil yangdidapatkan adalah 1)Rata-rata nilai siswa pada pre-test 78,494 dan post-test 94,40 . Hasil uji T-Test menunjukkan bahwa nilai $\mathrm{P}=0,000<\alpha 0,05$ yang berarti bahwa ada perbedaan yang signifikan nilai siswa pada pre-test dengan post-test, 2) praktekmassal menggosok gigi menunjukkan bahwa siswa sangat antusias dalam mengikuti praktek massal 3)Pendampingan bagi guru UKS berjalan dengan baikdansemakin menarik, karena adanya komitmen untuk menjalankan kegiatan UKS dan UKGS secara bertahap kepada siswa, 4) Sebagian besar siswa SD Negeri 5 Waai mengalami karies gigi yakni 81 siswa (92,06 \%), karang gigi 1 siswa $(1,13 \%)$ dan yang tidak mengalami karies gigi 6 siswa $(6,81 \%)$.
\end{abstract}

Kata Kunci: Karies Gigi, Penyuluhan, Praktek Masal, Pemeriksaan Gigi.

\begin{abstract}
The Community Partnership Program for students of Waai 5 Elementary School is based on the problem of the lack of student knowledge about dental caries and the School Health Effort (UKS) is also not implemented so that the School Dental Health Effort Program (UKGS) which is an integral part of UKS cannot be implemented. The purpose of this activity is to improve the knowledge and habits of brushing teeth, mentoring for teachers to create a UKS handbook, dental examinations to determine the severity of dental caries in students. The method used is mentoring with FGD methods, counseling, mass practice of brushing teeth, and examinations tooth. This activity was carried out in August 2019. The results obtained were 1) The average score of students in the pre-test was 78.494 and the post-test was 94.40. T-Test results show that the value of $P=0,000<\alpha 0.05$ which means that there are significant differences in student scores in the pre-test with the post-test, 2) mass practice of brushing teeth shows that students are very enthusiastic in participating in mass practice 3 ) Mentoring for UKS teachers is going well and increasingly interesting, because there is a commitment to carry out UKS and UKGS activities in stages to students, 4) Most students of SD Negeri 5 Waai experience dental caries which is 81 students $(92.06 \%)$, tartar 1 student $(1.13 \%)$ and who did not experience dental caries 6 students $(6.81 \%)$.
\end{abstract}

Keywords: Dental Caries, Counseling, Mass Practice, Dental Examination.

\section{PENDAHULUAN}

Karies gigi adalah penyakit jaringan gigi yang ditandai dengan kerusakan jaringan, dimulai dari permukaan gigi (ceruk, fisura dan daerah interproksimal) meluas ke arah pulpa. Karies gigi dapat dialami oleh setiap orang dan dapat timbul pada satu permukaan gigi atau lebih, serta dapat meluas ke bagian yang lebih dalam dari gigi, misalnya dari email ke dentin atau ke pulpa (Tarigan, 2013). Permasalahan karies gigi pada anak usia sekolah dasar menjadi penting karena karies gigi menjadi indikator keberhasilan upaya kesehatan gigi anak. Anak usia 6-14 tahun merupakan kelompok usia yang kritis dan mempunyai sifat khusus yaitu transisi/pergantian dari gigi susu ke gigi permanen (Rieza dkk, 2015).

Pada anak sekolah Karies gigi membuat anak mengalami kehilangan daya kunyah dan terganggunya pencernaan, yang mengakibatkan pertumbuhan kurang 
maksimal (Sinaga, 2013). Kondisi ini tentu akan mengurangi frekuensi kehadiran anak ke sekolah, mengganggu konsentrasi belajar, mempengaruhi nafsu makan dan asupan makanan sehingga dapat mempengaruhi status gizi dan pada akhirnya dapat mengakibatkan gangguan pertumbuhan fisik. Umumnya anak-anak memasuki usia sekolah mempunyai risiko karies yang tinggi karena pada usia sekolah ini anak-anak biasanya suka jajan makanan dan minuman sesuai keinginannya (Worotitjan dkk, 2013; Permatasari, 2014).

Banyak faktor yang dapat menimbulkan karies gigi pada anak, diantaranya adalah faktor di dalam mulut yang berhubungan langsung dengan proses terjadinya karies gigi, antara lain struktur gigi, morfologi gigi, susunan gigi-geligi di rahang, derajat keasaman saliva, kebersihan mulut yang berhubungan dengan frekuensi dan kebiasaan menggosok gigi, serta jumlah dan frekuensi makan-makanan yang menyebabkan karies (kariogenik). Selain itu, terdapat faktor luar sebagai faktor predisposisi dan penghambat yang berhubungan tidak langsung dengan terjadinya karies gigi antara lain usia, jenis kelamin, letak geografis, tingkat ekonomi, pengetahuan, sikap, dan perilaku terhadap pemeliharaan kesehatan gigi (Lanny, dkk. 2016).

Penelitian yang dilakukan oleh Norfai \& Rahman (2017) menunjukkan bahwa ada hubungan antara pengetahuan dan kebiasaan menggosok gigi dengan kejadian karies gigi di SD I Darul Mu'Minin Kota Banjarmasin Tahun 2017. Penelitian Maulida, dkk (2014) juga menunjukkan bahwa ada hubungan tingkat ekonomi, konsumsi makanan kariogenik dan kebiasaan menggosok gigi dengan kejadian karies gigi pada anak di TK Aisyiyah Bustanul Atfal Desa Lebaksiu Lor. Penelitian Tamrin dkk (2014), menunjukkan bahwa ada hubungan antara konsumsi makanan kariogenik dan kebiasaan menyikat gigi dengan kejadian karies gigi pada anak. Hasil Penelitian Widayati (2014) menggunakan uji Korelasi menunjukkan bahwa terdapat korelasi yang kuat antara kebiasaan memberi makan manis, lengket dan minum susu dengan kejadian karies gigi pada anak usia 4-6 tahun.

Riset Kesehatan Dasar (2013), prevalensi nasional karies aktif ialah $43,4 \%$. Sebanyak 14 provinsi memiliki prevalensi karies aktif diatas prevalensi Nasional yaitu Riau, Jambi, Sumatera Selatan, Bangka Belitung, Di Yogyakarta, Jawa Timur, Kalimantan Barat, Kalimantan Tengah, Kalimantan Selatan, Kalimantan Timur, Sulawesi Utara, Sulawesi Tengah, Sulawesi Tenggara, dan Maluku. Data tingkat provinsi di Indonesia, prevalensi karies aktif tertinggi (lebih dari $50 \%)$ ditemukan di Jambi $(56,1 \%)$, Kalimantan Barat dan Sulawesi Utara $(57,2 \%)$, Maluku $(54,4 \%)$, Riau (53,3\%), Lampung (54,9\%). Yogyakarta (52,3\%), Bangka Belitung (50,8\%), Kalimantan Selatan (50,7\%) Kalimantan Timur $(50,6 \%)$, Jawa Barat dan Sulawesi Selatan masing-masing 50,4\% (Riskesdas, 2013).
Berdasarkan hasil penelitian yang dilakukan oleh Rehena \& Kalay (2018) terhadap 32 siswa SD Negeri 5 Desa Waai menunjukkan bahwa yang mengalami karies gigi (gigi berlubang) sebanyak 28 siswa $(87,5 \%)$ dan hanya 4 siswa (12.5\%) yang tidak mengalami karies gigi, juga kurangnya pengetahuan siswa tentang karies gigi yakni 22 siswa $(68,8 \%)$ memiliki pengetahuan kurang tentang karies gigi, sebagian besar siswa yakni 26 siswa $(81,25 \%)$ memiliki kebiasaan makan makanan jajanan yang manis-manis (kariogenik), dan $87,5 \%$ memiliki kebiasaan menggosok gigi yang kurang baik yakni cara, waktu dan frekuensi menggosok gigi yang tidak benar dan tepat. Dengan demikian SD Negeri 5 Desa Waai dipilih oleh tim pelaksana Program Kemitraan Masyarakat Stimulus (PKMS) sebagai mitra dengan jumlah siswa 182 orang.

Masalah lainnya yang ditemukan saat melakukan wawancara langsung dengan Kepala Sekolah adalah tidak aktifnya UKS karena kurangnya peran guru UKS dan sarana prasarana yang tidak memadai seperti tidak adanya ruangan UKS. Berbagai program UKGS yang merupakan bagian integral dari UKS seperti penyuluhan tentang kesehatan gigi dan mulut, pemeriksaan dan pengobatan belum dilaksanakan secara berkala dengan baik. Penyuluhan tentang kesehatan gigi ini sering ditujukan pada anak-anak diharapkan mampu menjaga dirinya untuk mencegah terjadinya penyakit gigi dan mulut setelah dilaksanakan penyuluhan di sekolah, serta mampu mengambil tindakan yang tepat apabila ada gejala-gejala kelainan pada gigi dan mulutnya (Ringga, 2014).

Hasil wawancara dengan kepala SD Negeri 5 di Waai juga didapatkan informasi bahwa selama ini belum ada kegiatan penyuluhan tentang kesehatan gigi dan mulut, bahkan pemeriksaan gigi tidak dilakukan secara berkala, begitupun dengan program UKS dan UKGS yang tidak dijalankan karena minimnya sarana dan prasarana sekolah. Dengan demikian sangat diperlukan penyuluhan, praktek masal, pelatihan, pendampingan bagi siswa dan para guru sehingga dapat meningkatkan budaya perilaku hidup sehat dan bersih khususnya masalah karies gigi dapat dicegah sejak dini.

Berdasarkan gambaran permasalahan tersebut diatas maka tujuan dilaksanakan Program Kemitraan Masyarakat adalah untuk meningkatkan pengetahuan siswa melalui penyuluhan tentang karies gigi, faktorfaktor yang menyebabkan karies gigi, pengaruh karies gigi terhadap kesehatan siswa/i serta upaya pencegahannya dan untuk mengaktifkan kembali Program UKS maka dilakukan pendampingan bagi guru membuat buku panduan UKS dan program UKGS. Kegiatan praktek masal menggosok gigi dilakukan agar siswa dapat memahami dan menerapkan dalam kehidupannya sehari-hari dirumah. Pemeriksaan gigi dan mulut dilakukan agar siswa bisa mendapatkan informasi tentang keparahan karies dan disampaikan kepada orang tua untuk ditindaklanjuti. 


\section{BAHAN DAN METODE}

Metode yang digunakan adalah pendampingan bagi guru, penyuluhan/sosialisasi, praktek massal menggosok gigi, pemeriksaaan gigi. Metode yang digunakan dapat dijabarkan sebagai berikut: 1) Pendampingan bagi guru untuk membuat buku panduan bagi Pengelolaan UKS dan program UKGS, 2) Memberikan penyuluhan tentang karies gigi, faktorfaktor yang menyebabkan karies gigi, pengaruh karies gigi terhadap kesehatan siswa/i serta upaya pencegahannya. Penyuluhan menggunakan metode ceramah dan model pembelajaran picture and picture dengan media vidio animasi, 3) Gerakan/ praktek masal tentang cara menggosok gigi yang baik dan benar sehingga siswa dapat memahami dan menerapkan dalam kehidupannya sehari-hari dirumah, 4) Pemeriksaan gigi dan mulut untuk mengetahui karies gigi dan tingkat keparahannya pada siswa.

\section{HASIL DAN PEMBAHASAN}

Kegiatan pendampingan bagi guru UKS bertujuan agar guru mampu menyusun Buku pedoman UKS dan UKGS. Luaran yang diharapkan dari kegiatan ini adalah dihasilkannya Buku Pedoman bagi pengembangan UKS dan UKGS. Kegiatan pendampingan ini berlangsung pada hari Rabu 21 Agustus 2019, pukul 13.00 WIT, tempat pelaksanaan ruang Guru SD Negeri 5 Waai. Untuk memberikan gambaran tentang pelaksanaan program UKS dan UKGS di sekolah, tim menyiapkan draft pedoman pelaksanaan yang diberikan kepada guru dan dilengkapi/ ditambahkan kembali oleh tim, berdasarkan hasil Focus Group disucussion (FGD).

FGD berjalan dengan baik, dan guru menyampaikan kendala-kendala yang dihadapi dalam pelaksanaan Program UKS dan UKGS di sekolah. Pemateri yang menyampaikan gambaran umum pelaksanaan Program UKS dan UKGS di sekolah. Diskusi berlangsung menarik karena ada berbagai sharing tentang kendala yang dihadapi seperti sarana/ fasilitas yang tidak dijaga dengan baik, tidak adanya ruang UKS, pelaksanaan pemeriksaan gigi di sekolah yang tidak rutin. Diskusi menjadi semakin menarik, karena ada komitmen bersama dari Kepala Sekolah dengan guru untuk menjalankan kegiatan UKS dan UKGS secara bertahap kepada peserta didik melalui aksi-aksi sederhana yang terus berlanjut.

Hasil diskusi menyimpulkan bahwa pentingnya Program UKS dan UKGS di sekolah seperti menghadirkan dokter gigi dan petugas kesehatan untuk pemeriksaan gigi sejak dini dan berkelanjutan, membuat dokter cilik.Pentingnya sosialisasi bagi orang tua sehingga mendapat dukungan agar ritme penerapan Pola Hidup bersih dan sehat seperti cara menggosok gigi yang baik dan benar dapat terjaga pelaksanaannya hingga di rumah.
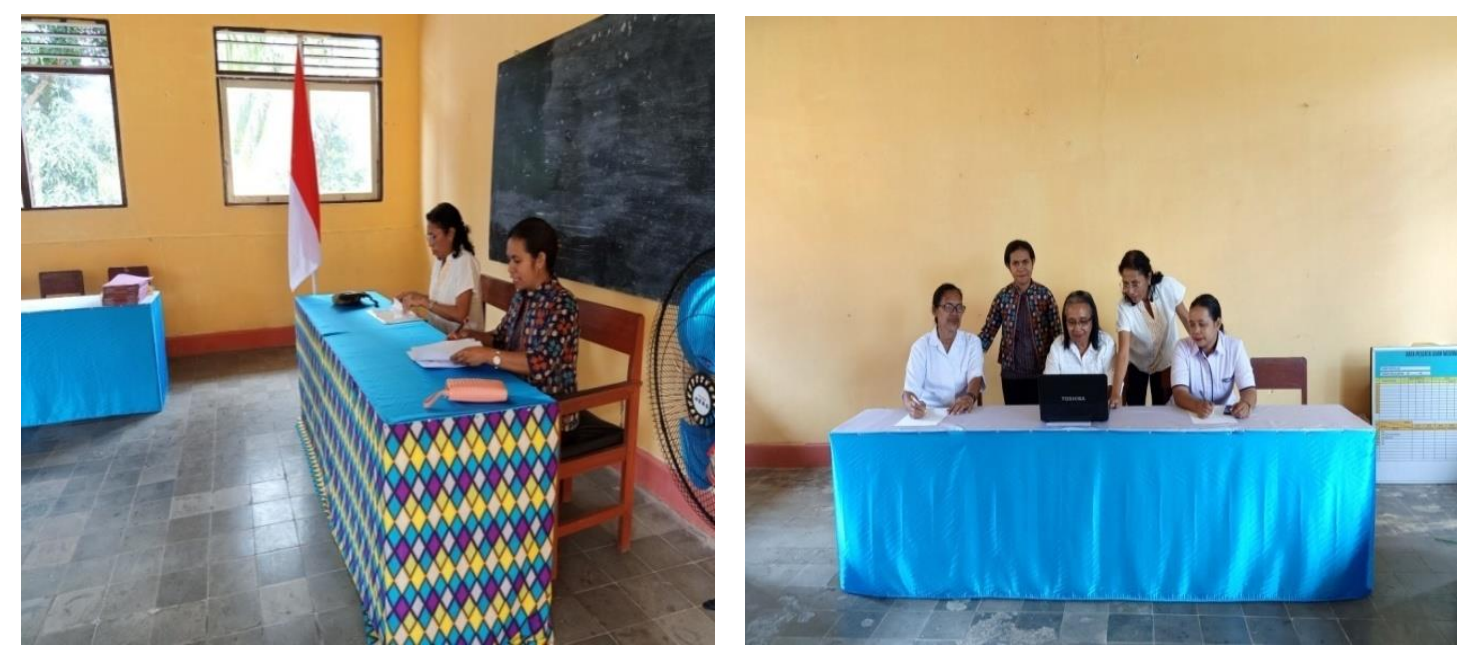

Gambar 1. Pendampaingan bagi guru UKS.

Kegiatan penyuluhan berlangsung pada hari kamis, 22 Agustus 2019 pukul 09.00 WIT di SD Negeri 5 Waai. Untuk memudahkan pemahaman siswa/i, tim menggunakan vidio animasi yang berisi materi tentang karis gigi pada anak sekolah. Selain itu juga digunakan lembar pretest dan posttest yang berisi 10 pertanyaan tentang karies gigi, yang dijawab oleh siswa/i dengan menyilang pada pilihan benar (B) atau salah (S).
Siswa dibagi atas 2 kelas yaitu gabungan kelas II dan III, gabungan kelas IV dan V dengan total jumlah siswa yang hadir adalah 93 orang. Penyuluhan diawali dengan pembagian lembar pretest untuk mengukur tingkat pengetahuan siswa. Selanjutnya penyampaian materi dilakukan oleh Tim (dosen). Setelah penyampaian materi, dilakukan evaluasi dengan menggunakan lembar posttest untuk melihat ada tidaknya peningkatan pengetahuan siswa. Siswa mengumpulkan lembar posttest. kegiatannya penyuluhan dapat dilhat pada gambar 2. 

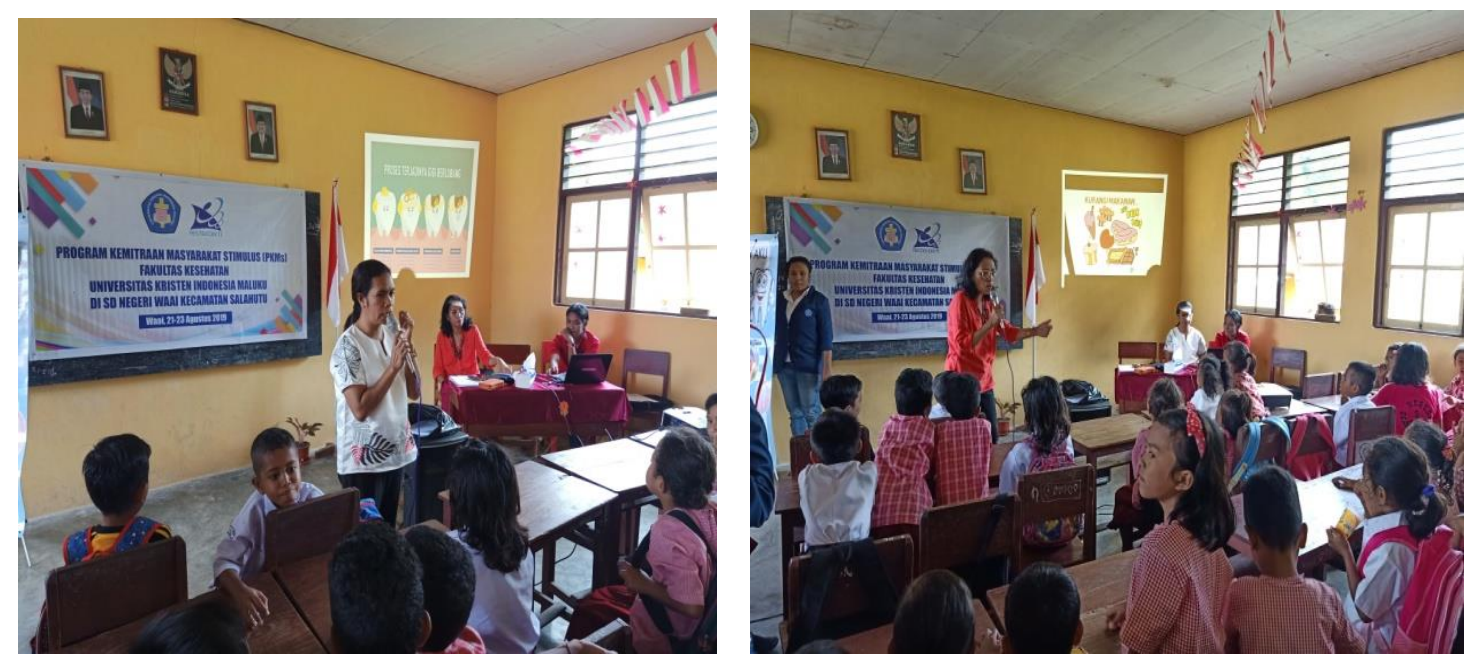

Gambar 2. Kegiatan Penyuluhan.

Deskripsi pengetahuan siswa pada saat Pretest (sebelum penyuluhan) dan Posttest (setelah penyuluhan) Siswa SD Negeri 5 Waai dapat dilihat pada Tabel 1.

Tabel 1. Hasil Pretest dan Post test Siswa SD Negeri 5 Waai.

\begin{tabular}{|c|c|c|c|c|c|}
\hline \multirow{2}{*}{ Kelas } & \multirow{2}{*}{ Kategori Nilai } & \multicolumn{3}{|c|}{ Pretest } & \multirow{2}{*}{$\begin{array}{c}\text { Posttest } \\
\%\end{array}$} \\
\hline & & $\mathbf{n}$ & $\%$ & $\mathbf{n}$ & \\
\hline \multirow{2}{*}{ II } & Cukup $(\leq 70)$ & 8 & 32 & 2 & 8 \\
\hline & Baik(> 70) & 17 & 68 & 23 & 92 \\
\hline \multirow{2}{*}{ III } & Cukup $(\leq 70)$ & 9 & 36 & 2 & 8 \\
\hline & Baik $(>70)$ & 16 & 64 & 23 & 92 \\
\hline \multirow{2}{*}{ IV } & Cukup $(\leq 70)$ & 8 & 35 & 0 & 0 \\
\hline & Baik (>70) & 12 & 65 & 20 & 100 \\
\hline \multirow{2}{*}{$\mathrm{V}$} & Cukup $(\leq 70)$ & 5 & 17,3 & 0 & 0 \\
\hline & Baik $(\leq 70)$ & 18 & 82,6 & 23 & 100 \\
\hline \multirow{2}{*}{ TOTAL } & Cukup $(<70)$ & 30 & 32,3 & 4 & 4,3 \\
\hline & Baik (> 70) & 63 & 67,7 & 89 & 95,7 \\
\hline
\end{tabular}

Tabel 1menunjukan bahwa ada peningkatan nilai siswa dengan kategori nilai baik (> 70) pada posttest dibandingkan pretest, persentase peningkatan tertinggi pada kelas IV dan V yaitu meningkat menjadi $100 \%$ pada posttest. Hal ini menunjukan bahwa terjadi peningkatan pengetahuan pada siswa setelah diberikan penyuluhan dengan menggunakan metode ceramah dan model pembelajaran Picture and picture dengan media vidio animasi. Berdasarkan hasil tersebut maka dilakukan uji T-test untuk mengetahui perbedaan nilai test sebelum dilakukan penyuluhan (pre-test) dan nilai sesudah penyuluhan (post-test). Hasil uji T-test dapat dilihat pada tabel 2 .

Tabel 2. Hasil Uji T-Test.

\begin{tabular}{|l|c|c|c|c|c|c|c|}
\hline & & Mean & N & Std. Deviation & t & df & $\begin{array}{c}\text { Sig. (2- } \\
\text { tailed) }\end{array}$ \\
\hline \multirow{2}{*}{ Pair 1 } & Pre-Test & 78,494 & 93 & 10,829 & \multirow{2}{*}{$-19,250$} & \multirow{2}{*}{92} & \multirow{2}{*}{0,000} \\
\cline { 2 - 5 } & Post-Test & 94,408 & 93 & 7,866 & & & \\
\hline
\end{tabular}

Hasil analisis pada Tabel 2 menunjukkan bahwa ratarata nilai siswa sebelum mendapat penyuluhan (pre-test) adalah 78,494 dan sesudah mendapat penyuluhan (posttest) adalah 94,408. Hasil ini menunjukkan bahwa ada peningkatan pengetahuan siswa setelah mendapat penyuluhan tentang karies gigi dan faktor-faktor yang menyebabkan karies gigi. Hasil Uji T-Testyang terlihat pada tabel 1 menunjukan bahwa nilai $P$ value yang dapat dilihat pada sig (2 tailed) adalah $0,000<\alpha 0,05$ yang 
berarti bahwa ada perbedaan yang signifikan antara nilai siswa pada pre-test dengan nilai post-test.

Setelah selesai kegiatan penyuluhan dan post-testmaka dilanjutkan dengan kegiatan praktek massal menggosok gigi. Praktek massal dilakukan dengan tujuan memperkuat pemahaman dan melatih siswa untuk langsung mempraktekkan cara menggosok gigi yang baik dan benar dan saat siswa kembali dirumah mereka dapat mempraktekan hal itu dalam kehidupan seharihari sekaligus sebagai suatu tindakan pencegah masalah karies gigi. Praktek massal juga penting dilakukan sehingga siswa dapat mengingat materi yang diberikan dengan lebih baik. Kegiatan praktek massal memerlukan alat dan bahan yang telah disediakan oleh tim antara lain sikat gigi, odol gigi, gelas untuk kumurkumur, penampungan air, dan sabun cuci tangan.
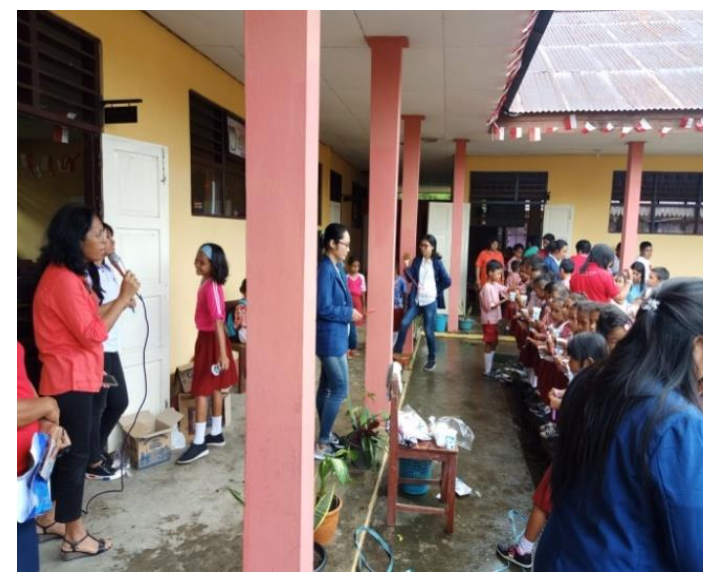

Gambar 3. Praktek masal menggosok gigi.

Pemeriksaan gigi merupakan kegiatan terakhir dari kegiatan PKMS yang dilakukan untuk mengetahui ada tidaknya karies gigi pada siswa yang disebabkan karena adanya bakteri, waktu dan lama menggosok gigi, makanan dan minuman yang mains-manis. Pemeriksaan gigi di SD Negeri 5 Waai, dilakukan pada Jumat, 23 Agustus 2019. Pemeriksaan gigi dilakukan pada pukul 09.00 WIT oleh Dokter gigi Rachmawaty dan didampingi oleh salah satu petugas kesehatan yang keduanya juga bertugas pada Wilayah Puskesmas Waai. Pemeriksaan gigi dilakukan pada 88 siswa SD Negeri 5 Waai. Hasil Pemeriksaan gigi dapat dilihat pada Tabel 3
Praktek massal diawali dengan mempersiapkan perlengkapan praktek seperti air dalam penampung air, sikat gigi, pasta gigi, gelas plastik untuk kumur-kumur, sabun cair untuk mencucui tangan. Untuk memudahkan, siswa dalam praktek menggosok gigi maka siswa dipandu secara serempak oleh tim berdasarkan tahapan menggosok gigi yang baik dan benar. Selanjutnya peserta didik dibagikan sikat dan pasta gigi, dan mempraktekan cara menggosok gigi yang benar.

Peserta didik sangat antusias dalam mengikuti kegiatan praktek massal. Untuk mengefisienkan pelaksanaan praktek massal, tim melibatkan 3 - 4 orang mahasiswa yang membantu dalam kegiatan PKMS, 1 orang petugas kesehatan, dokter gigi, dan guru wali kelas. Setelah praktek massal selesai dilakukan, peserta didik diberi makanan. Kegiatan praktek massal menggosok gigi dapat dilihat pada gambar berikut.

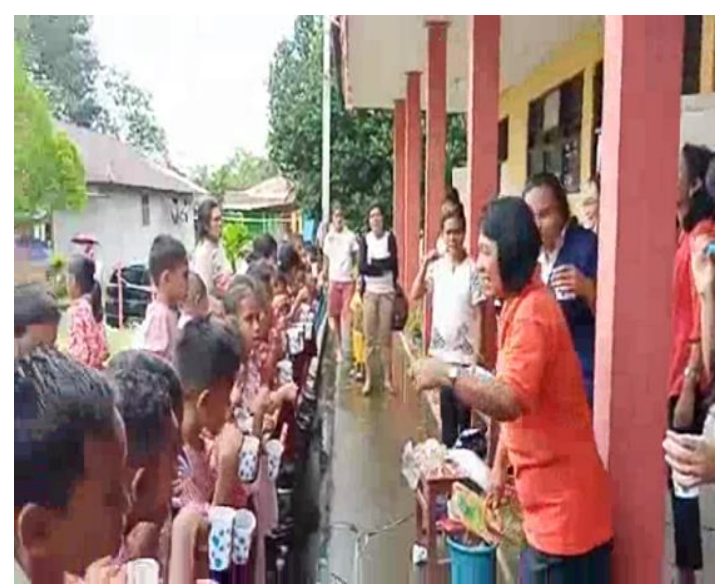

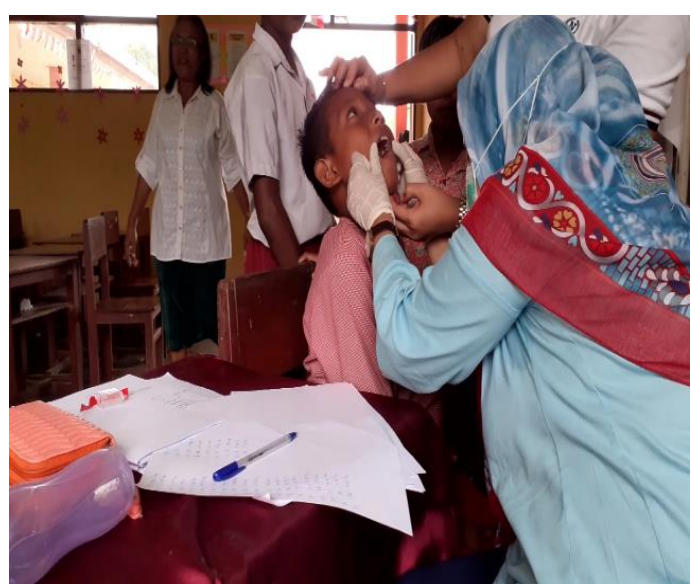

Gambar 4. Pemeriksaan Gigi

Tabel 3. Hasil Pemeriksaan Gigi pada Siswa SD Negeri 5 Waai.

\begin{tabular}{|c|c|c|c|}
\hline $\begin{array}{c}\text { Jumlah gigi yang berlubang, } \\
\text { tidak berlubang dan } \\
\text { karanggigi }\end{array}$ & Jumlah siswa & $\begin{array}{c}\text { Persentasi } \\
(\boldsymbol{\%})\end{array}$ & $\begin{array}{c}\text { Cara Penanganan yang } \\
\text { dianjurkan dokter }\end{array}$ \\
\hline 1 & 8 & 9,09 & Tambal \\
\hline 2 & 10 & 11,36 & Tambal, konservasi \\
\hline 3 & 7 & 7,95 & Tambal, cabut \\
\hline
\end{tabular}




\begin{tabular}{|c|c|c|c|}
\hline 4 & 11 & 12,50 & Tambal, cabut, konservasi \\
\hline 5 & 6 & 6,81 & Tambal, cabut, konservasi \\
\hline 6 & 10 & 11,36 & Tambal, cabut, konservasi \\
\hline 7 & 6 & 6,81 & Tambal, cabut, konservasi \\
\hline 8 & 4 & 4,54 & Tambal, cabut, konservasi \\
\hline 9 & 5 & 5,68 & Tambal, cabut, konservasi \\
\hline 10 & 8 & 9,09 & Tambal, cabut, konservasi \\
\hline 11 & 2 & 2,27 & Tambal, cabut, konservasi \\
\hline 12 & 2 & 2,27 & Tambal, cabut, konservasi \\
\hline 13 & 1 & 1,13 & Tambal, cabut, konservasi \\
\hline Tidakberlubang & 6 & 6,81 & - \\
\hline Karanggigi & 1 & 1,13 & konservasi \\
\hline Total & 88 & 100 & \\
\hline
\end{tabular}

Hasil pemeriksaan gigi yang terlihat pada Tabel 4.5 menunjukan bahwa hampir semua siswa di SD Negeri 5 Waai mengalami karies gigi (gigi berlubang) yakni 81 siswa $(92,06 \%)$, karang gigi 1 siswa $(1,13 \%)$ dan yang tidak mengalami karies gigi hanya 6 siswa $(6,81)$. Cara penanganan maalah karies gigi yang dianjurkan dokter adalah tambal, cabut dan juga konservasi gigi. Untuk memelihara kesehatan gigi dan mulut, dapat dilakukan upaya promosi kesehatan untuk meningkatkan perilaku hidup bersih dan sehat melalui program UKS dan UKGS, media cetak maupun elektronik, penyuluhan langsung, bimbingan dan konseling, intervensi perubahan perilaku. Perilaku hidup bersih dan sehat dilakukan sejak dini agar terhindar dari masalah kesehatan terutama kesehatan gigi dan mulut.

\section{KESIMPULAN}

Kesimpulan dari Program Kemitraan Masyarakat Stimulus (PKMS) bagi siswa SD Negeri 5 Desa Waai antara lain :

1. Kegiatan pendampingan bagi guru UKS dengan metode Focus Discussion Group mendorong pimpinan sekolah dan guru untuk melaksanakan program UKS dan UKGS secara berkala serta menghasilkan buku panduan pelaksanaan program UKS dan UKGS.

2. Kegiatan penyuluhan bagi siswa SD Negeri 5 Waai tentang karies gigi dapat meningkatkan pengetahuan siswa dengan hasil yang diperoleh yaitu rata-rata nilai pada pretest adalah 78,494 meningkatkan pada posttestadalah 94,408. Hasil Uji $\mathrm{T}$ berpasangan menunjukan bahwa ada perbedaan yang signifikan antara nilai siswa pada pre-test dengan nilai post-test

3. Kegiatan praktek massal yang telah dilaksanakan adalah praktek cara menggosok gigi yang baik dan benar

4. Hampir semua siswa di SD Negeri 5 Waai mengalami karies gigi (gigi berlubang) yakni 81 siswa $(92,06 \%)$, karang gigi 1 siswa $(1,13 \%)$ dan yang tidak mengalami karies gigi hanya 6 siswa $(6,81)$.

\section{UCAPAN TERIMA KASIH}

Ucapan terima kasih penulis sampaikan kepadaDirektorat Riset dan Pengabdian Kepada Masyarakatyang telah memberikan bantuan pendanaan kepadapenulis melalui skema pendanaan Program KemitraanMasyarakat Stimulus (PKMS) tahun 2019.

\section{DAFTAR PUSTAKA}

Lanny, S., Salikun., \& Ningrum, P, W. (2016). Faktor Penyebab Tingginya Angka Karies Gigi Tetap Pada Siswa SD Negeri 02 Banjarsari Kecamatan Talun Kabupaten Pekalongan. Jurnal ARSA (Actual Research ScieneAcademic), Vol 1 No 1, November 2016.

Maulida, S., Gayuh, S. L., \& Oktiawati, A. (2014). Faktor-Faktor Yang Berhubungan Dengan Kejadian Karies Gigi Pada Anak Di Tk Aisyiyah Bustanul Atfal Desa Lebaksiu Lor. Jurnal Keperawatan Anak . Volume 2, No. 2, November 2014; 108-115.

Norfai \& Rahman, E. (2017). Hubungan Pengetahuan dan Kebiasaan Menggosok Gigi dengan Kejadian Karies Gigi Di SDI Darul Mu'minin Kota Banjarmasin Tahun 2017. Dinamika Kesehatan, Vol. 8 No. 1, Juli 2017.

Permatasari, I., \& Andhini, D. (2014). Hubungan Perilaku Menggosok Gigi Dan Pola Jajan AnakDengan Kejadian Karies Gigi Pada Murid SD Negeri 157 Palembang. Jurnal Keperawatan Sriwijaya, Volume 1 - Nomor 1, Juli 2014, ISSN No 23555459.

Rehena, Z., \& Kalay, M. (2018). Faktor - Faktor yang Berhubungan dengan kejadian Karies Gigi Pada Murid Kelas 1 SD Negeri 5 Waai. Laporan Penelitian. Ambon. Fakultas Kesehatan, Universitas Kristen Indonesia Maluku.

Rieza, Z.T., Rismayani, L., Santoso, B., \& Wiyatini, T. (2015). Analisis Program Kegiatan Usaha Kesehatan Gigi Sekolah (UKGS) di Puskesmas Halmahera. Jurnal Kesehatan Gigi. Vol 02, No 1, Juni 2015.

Ringga, S., Rosihan , A., Sukmana, B. I., \& Hadianto,T. (2014). Hubungan Pelaksanaan UKGS Dengan Status Kesehatan Gigi Dan Mulut Murid Sekolah Dasar Dan Sederajat Di Wilayah Kerja Puskesmas Cempaka Putih Kota Banjarmasin. Dentino Jurnal Kedokteran Gigi, Vol II. No 1. Maret 2014. 
Riskesdas. (2013). Laporan Riset Kesehatan Dasar. Badan Penelitian danPengembangan Kesehatan. Kementerian Kesehatan RI.

Sinaga A. (2013). Faktor-faktor yang Berhubungan dengan perilaku Ibu dalam Mencegah Karies Gigi Anak Usia 1-5 Tahun di Puskesmas Babakan Sari Bandung. Jurnal Darma Agung. XXI: $1-10$.

Tamrin, M., Afrida., \& Jamaludin, M. (2014). Dampak Konsumsi Makanan Kariogenik dan Kebiasaan Menyikat Gigi Terhadap Kejadian Karies Gigi Pada Anak Sekolah ., Journal of pediatricnursing, Vol.1 (1), Januari, 2014: 14-18.

Tarigan, R. (2013). Karies gigi edisi 2. Jakarta: Penerbit Buku Kedokteran EGC. Hal 15-90.

Widayati, R. (2014). Faktor Yang Berhubungan Dengan Karies Gigi Pada AnakUsia 4-6 Tahun, Jurnal Berkala Epidemiologi, Vol. 2, No. 2 Mei 2014: 196-205.

Worotitjan, I., Mintjelungan N., Christy, \& Gunawan, P. (2013). Pengalaman karies gigi serta pola makan dan minum pada anak Sekolah Dasar di desa kiawa kecamatan kawangkoan utara. Jurnal eGiGi (eG); 2013 mar:1(1):60-8. 